\title{
ARTIGOS
}

\section{CONTRIBUIÇÕES DA PROFESSORA MARLI ANDRÉ PARA A PRODUÇÃO DE CONHECIMENTO SOBRE PROFESSORES INICIANTES}

Emília Freitas de LIMA

Universidade Federal de São Carlos - UFSCar

São Carlos - SP - Br

emilia@ufscar.br

https://orcid.org/0000-0002-6916-130X

\begin{abstract}
RESUMO: $O$ artigo analisa as principais produções acadêmicas da Professora Marli André sobre o estudo dos professores iniciantes, selecionadas em seu CV Lattes, nas abas Projetos, Produções, Eventos e Orientações, por meio dos seguintes termos de busca: iniciante; principiante; ingressante; início da docência; indução profissional; e inserção profissional. Após analisar os trabalhos, apresenta destaques analíticos relacionados a: políticas e programas de inserção/indução profissional; conceitos-chave - desenvolvimento profissional docente; formação continuada; professores iniciantes, ingressantes e indução profissional; diretores iniciantes; necessidades formativas; e metodologia de pesquisa. Chama a atenção para a contribuição da produção de Marli André para a elaboração de políticas públicas e, em consequência, desautoriza as autoridades governamentais e das agências de fomento à pesquisa a alegarem a ausência de contribuição de pesquisadores e pesquisadoras brasileiras para este mister. Finalmente, convida pesquisadores(as) interessados(as) na temática da construção profissional do início da docência a revisitarem o texto para complementá-lo ou debater a leitura exposta nele sobre as produções de Marli André.
\end{abstract}

PALAVRAS-CHAVE: Professor iniciante. Desenvolvimento profissional docente. Formação continuada. Necessidades formativas. 


\title{
CONTRIBUTIONS OF PROFESSOR MARLI ANDRÉ TO THE PRODUCTION OF KNOLEDGE ABOUT BEGINNER TEACHERS
}

\begin{abstract}
The article analyses the main academic productions of the Professor Marli Andre on the study of beginning teachers selected in her CV Lattes, in the Projects, Productions, Events and Orientations tabs, with the search terms: beginner; incoming; beginning of teaching; professional induction; and professional insertion. After analyzing the texts, it presents analyzes related to policies and programs for professional insertion/induction; the key concepts of professional teacher development; continuing education; beginning, freshman and professional induction teachers; beginning directors; training needs; and research methodology. After analyzing the works, it presents analyzes related to policies and programs for professional insertion/induction; the key concepts of professional teacher development; continuing education; beginning, incoming teachers and professional induction; beginning directors; training needs; and research methodology. It highlights the author's relevant contribution to the elaboration of public policies, which disqualifies government authorities and development agencies from claiming the absence of contributions from Brazilian researchers to this task. Invites professionals interested in the subject under analysis to complement the text or discuss the reading exposed in it about the productions of Marli André.
\end{abstract}

KEYWORDS: Beginning teacher. Teacher professional development. Continuing traininig. Formative needs.

\section{CONTRIBUTIONS DE LA PROFESSEURE MARLI ANDRÉ À LA PRODUCTION DE CONNAISSANCES SUR LES PROFESSEURS DÉBUTANTS}

RÉSUMÉ: L'article analyse les principales productions académiques de la professeure Marli André sur l'étude des enseignants débutants, sélectionnées dans son CV Lattes, dans les onglets Projets, Productions, Evénements et Orientations, à travers les termes de recherche suivants: débutant; entrant; début de l'enseignement; intégration professionnelle; et l'insertion professionnelle. Après I'nalyse des travaux, il présente les faits saillants relatifs: aux politiques et programmes d'insertion/induction professionnelle; concepts clés - développement professionnel des enseignants; formation permanente; enseignants débutants, entrants et d'initiation professionnelle; gestionnaires débutants; besoins de formation; et méthodologie de recherche. II attire l'attention sur la contribution de la production de Marli André à l'élaboration des politiques publiques et, de ce fait, interdit aux autorités gouvernementales et aux agences de financement de la recherche de revendiquer le manque de contribution des chercheurs brésiliens à cette tâche. Enfin, il invite les chercheurs intéressés par le thème de la construction professionnelle du début dienseignement à revisiter le texte pour le compléter ou débattre la lecture des productions de Marli André exposée dedans.

MOTS-CLÉS: Enseignement débutant. Dévelopment professionnel des enseignants. Formation permanente. Besoins de formation. 


\section{Introdução}

Sinto-me envolvida por duplo sentimento: um prazer enorme em reverenciar a memória de uma das pesquisadoras mais influentes e contributivas na história da pesquisa em Educação no Brasil; uma imensa tristeza por ser um texto póstumo.

Tive o privilégio de privar da proximidade com Marli tanto no plano acadêmico quanto pessoal. Conheci-a em 1977, na PUC-Rio, quando fazia o Mestrado e ela chegava dos Estados Unidos com o doutorado recém-concluído. Dessa época guardo muitas lembranças, especialmente a da participação dela na minha banca de mestrado, em 1978 - sua primeira participação em bancas. Depois ela me segredou que não sabia quem havia ficado mais nervosa, se eu ou ela. Em 1996, voltou a participar da minha banca de defesa de doutorado, outro fato marcante para mim.

Também foi inestimável sua contribuição efetiva ao GT8-Formação de Professores da ANPEd, dando a mim e a Laurizete enorme apoio nas nossas duas gestões como coordenadoras do GT. Destaco o seu incentivo e ajuda decisivos à realização do I Simpósio sobre Formação de Professores no Brasil, ainda na nossa gestão à frente do GT8.

Sou-lhe grata pelas inúmeras participações em bancas de mestrandos e doutorandos orientados por mim, além dos inúmeros convites que me fez para participar nas de orientandos seus. Foram ocasiões de muita aprendizagem, além da vivência de grandes emoções, como numa banca em que ela estava recém-viúva e recebeu da doutoranda uma homenagem que nos fez chorarmos juntas.

Enfim, Marli não foi apenas uma pesquisadora e produtora de conhecimento sobre pesquisa e formação de professores no Brasil, com importante inserção internacional; foi alguém com quem muito aprendi e a quem sempre agradecerei.

Neste texto, após muito pensar sobre o que abordar, decidi analisar - de forma não exaustiva, obviamente sua contribuição sobre o estudo dos professores iniciantes. Inicio explicando os procedimentos que adotei na elaboração do trabalho e, em seguida, analiso parte da produção da autora sobre o tema e formulo alguns destaques.

\section{Caracterizando o trabalho}

De tipo bibliográfico, o artigo analisa textos obtidos por meio da consulta à página do CV Lattes de Marli André, especialmente nas abas 'Projetos', 'Produções', 'Eventos' e 'Orientações'. Aos registros contidos em cada uma delas apliquei os seguintes termos de busca: 'iniciante'; 'principiante'; 'ingressante'; 'início da docência'; 'indução profissional'; e 'inserção profissional', obtendo o seguintes resultado:

\section{Quadro 1. Produção acadêmica da Professora Marli André sobre professores iniciantes}

\begin{tabular}{|l|l|}
\hline TlPO & N \\
\hline Artigos publicados em periódicos & 13 \\
\hline Capítulos de livros & 06 \\
\hline Trabalhos completos em anais de eventos & 08 \\
\hline
\end{tabular}




\begin{tabular}{|l|l|}
\hline Resumos expandidos em anais de eventos & 02 \\
\hline Orientações de mestrado & 03 \\
\hline Orientações de doutorado & 04 \\
\hline Projetos de pesquisa (duração de 3 anos cada) & 03 \\
\hline
\end{tabular}

Fonte: CV Lattes da Professora Marli André.

Estes registros mostram que o tema 'professor iniciante', e termos correlatos, passa formalmente a fazer parte da produção acadêmica de Marli em 2010, quando assume a orientação da tese de doutorado de Ana Maria Gimenes Calil, cuja defesa se deu em 2014 (CALIL, 2014).

Em 2011 dá início à pesquisa denominada "Aproximação entre universidade e escola na formação de professores: políticas de Inserção na Docência" (2011-2014), seguida de duas outras: "Inserção profissional de egressos de programas de iniciação à docência" (2015-2018) e "Processos de Indução de professores iniciantes na escola, básica", iniciada em 2019 e, lamentavelmente, inconclusa.

Este texto analisa a parte desta produção composta por artigos publicados em periódicos e as dissertações e teses orientadas, todos relacionados às pesquisas mencionadas.

\section{Apresentando a produção}

Considerando-se o conjunto da produção em análise, pude distinguir dois grupos de trabalhos.

O primeiro diz respeito a políticas e programas de apoio a docentes iniciantes:

- Artigos - André (2012; 2013; 2015; 2018); André, Alfonsi e Bachiega (2014); Giordan, Hobold e André (2014); Calil e André (2016); Signorelli'; André (2019), os dois últimos oriundos de teses orientadas por ela;

- Dissertações e teses: Francisco (2020); Calil (2014); Signorelli (2016).

- O segundo envolve trabalhos voltados à compreensão do processo de início da docência e um deles a diretores de escola iniciantes:

- Artigos - André, Calii, Martins; Pereira (2017); Giordan; Hobold; André (2017); Príncepe; André (2018); Hees; André (2018); Príncepe; André (2019), os 3 últimos derivados de dissertações e teses.

- Dissertações e teses: Hees (2016); Príncepe (2017); Silva (2018); Diniz (2020).

\subsection{Sobre políticas e programas de apoio a docentes iniciantes}

O CV Lattes indica que a autora publicou 4 artigos de autoria única envolvendo o tema 'professores iniciantes', 3 dos quais advieram da pesquisa de Gatti, Baretto e André (apud ANDRÉ 2012; 2013; 2015)². Destes, dois versavam sobre formação continuada em geral, com análises referentes aos professores iniciantes (ANDRÉ,

1 Esta autora ora aparece referenciada como Signorelli, ora como Gonçalves.

2 GATTI, Bernardete A.; BARRETTO, Elba Siqueira S.; ANDRÉ, Marli E. D. A. Políticas docentes no Brasil: um estado da arte. Brasília, DF: UNESCO, 2011. 300p. 
2013; 2015); em um deles estes últimos foram especificamente focalizados (ANDRÉ, 2012). O quarto artigo (ANDRÉ, 2018) adveio de outra pesquisa.

Os artigos "Políticas de apoio aos docentes em estados e municípios brasileiros: dilemas na formação de professores" (ANDRÉ, 2013) e "Políticas de formação continuada e de inserção à docência no Brasil" (ANDRÉ, 2015) versam sobre políticas voltadas aos docentes da educação básica com base em dados coletados em quinze secretarias de educação de estados e municípios brasileiros.

O primeiro deles (ANDRÉ, 2013) descreve e analisa as experiências que favorecem a inserção profissional dos professores iniciantes em 3 municípios apresentados como exemplos: Jundiaí, Sobral e Campo Grande.

No segundo (ANDRÉ, 2015) é dado realce a programas oferecidos por 2 estados (Espírito Santo e Ceará) e 2 municípios (Sobral/CE e Jundiaí/SP) estes últimos já analisados em André (2013). Ela justifica o destaque atribuído a esses 2 municípios por seguirem a direção indicada pelo relatório da OCDE (2006) e por autores como Imbernón e Vaillant (apud ANDRÉ, 2015).

São também analisados programas como o "Pibid"3 (nacional); o "Bolsa Alfabetização" (estadual/SP); e o "Bolsa Formação Aluno-Aprendizagem" (municipal/Jundiaí / SP).

No conjunto dos 2 artigos, chamaram a minha atenção aspectos como:

- Exiguidade de iniciativas de secretarias de educação quanto ao levantamento de necessidades formativas dos docentes, ao contrário da defesa que a autora faz do atendimento a estas necessidades, com base em Rodrigues (2006, apud ANDRÉ, 2013) para quem o levantamento e análise das necessidades formativas dos docentes representa uma estratégia de desenvolvimento da competência reflexiva;

- Os programas, em geral, tomam como base um professor genérico, e não acompanham os efeitos das ações docentes na escola e sala de aula. Além disso, centram-se em Português e Matemática, o que merece forte crítica da autora, e são elaborados sem a participação dos professores;

- Quanto ao PIBID, a autora informa que embora não houvesse, àquela altura, avaliação abrangente de seus efeitos, avaliações pontuais indicavam resultados muito positivos quanto: à motivação dos participantes para ingressarem na profissão; à disposição dos professores das escolas, por se sentirem desafiados a rever suas práticas em colaboração com os novos atores. Já os outros 2 programas são descritos, porém sem alusão a resultados de avaliação de seus resultados;

- As experiências de Sobral/CE e de Campo Grande/MS são valorizadas por André (2015) pelo fato de suas políticas de formação serem constituídas por "ações articuladas, sistemáticas, centradas na prática escolar, com incentivos aos docentes para participarem dos encontros de formação, acompanhamento na escola, avaliação dos seus efeitos na aprendizagem dos alunos e revisão da formação" (p. 43). Tais aspectos, segundo a autora, representariam um avanço em relação à maioria das iniciativas, que evidenciariam "o caráter individualizado das ações formativas e a falta

3 “Criado em 2007, o Pibid é um programa de fomento cujo propósito é proporcionar a estudantes de licenciatura a oportunidade de atuarem como profissionais na educação básica por meio da inserção em escolas da rede pública onde possam criar e participar de experiências de caráter inovador e interdisciplinar, que articulem as diferentes áreas do conhecimento e promovam a relação entre teoria e prática. Prevê a concessão de bolsas aos estudantes, aos docentes da universidade que os orientam e aos professores da escola básica que os recebem em suas salas de aula" (ANDRÉ, 2015, p. 43). 
de instrumental avaliativo para verificar seu efeito no desenvolvimento profissional do professor e na prática de sala de aula" (p. 43);

- Mesmo assim, ela aponta um avanço das ações formativas, por deixarem de ser dispersas e focarem no desenvolvimento das propostas curriculares, embora critique o atrelamento dessas ações aos resultados das avaliações externas;

- Indica a necessidade de valorização e ampliação da parceria universidade-escola, por possibilitar a superação do divórcio entre os espaços de formação e os do exercício profissional, além de auxiliarem os estudantes a se identificar com a profissão e favorecerem a inserção à docência.

Especificamente voltado ao tema dos professores iniciantes há o artigo "Políticas e programas de apoio aos professores iniciantes no Brasil" (ANDRÉ, 2012), em que ela parte da pergunta "Existem políticas voltadas aos professores iniciantes no Brasil?" (p. 112) e, para respondê-la, recorre aos dados da pesquisa de Gatti et al. (apud ANDRÉ, 2013; 2015) já mencionada.

Analisa, então, as ações formativas voltadas aos professores iniciantes, em seguida à sua aprovação no concurso de ingresso. Retoma a análise das ações realizadas em Sobral/CE e Campo Grande/MS e dos 3 programas de parceria universidade- escola referenciados em André (2015). Considera tais ações promissoras no intuito de amenizar as dificuldades do início da docência, embora fossem ainda muito recentes à época da realização da pesquisa.

O outro artigo com foco específico nos professores iniciantes foi "Professores iniciantes: egressos de programas de iniciação à docência" (ANDRÉ, 2018), objetivando analisar o processo de inserção profissional de professores iniciantes, egressos de três programas de iniciação à docência: PIBID, Bolsa Alfabetização e Residência Pedagógica da UNIFESP/Guarulhos.

Os conceitos de socialização profissional, clima institucional e inserção profissional fundamentaram a pesquisa, cuja metodologia envolveu a realização de uma survey com 1.237 egressos oriundos de 18 instituições de ensino superior das regiões brasileiras Nordeste, Centro-Oeste, Sul e Sudeste. Os resultados indicaram que $67 \%$ dos egressos estavam atuando na educação, muitos em escolas públicas (61\%); a maioria declarou receber apoio e reconhecimento dos colegas, gestores e pais de alunos e obter respostas positivas dos alunos. Metade dos respondentes declarou pouca satisfação com o número de alunos por classe e com o salário.

No artigo "Um momento importante na formação dos licenciandos do PIBID: a transição de aluno a professor e a constituição de sua identidade profissional", os autores (BARBOSA; ALFONSI; BACHIEGA; ANDRÉ, 2014a) buscaram "identificar como discentes participantes do PIBID percebem seu processo de formação, bem como quais concepções e intenções revelam em relação à docência" (p. 302), além de "entender o processo de transição de aluno a professor" (p. 306).

A pesquisa se deu por meio de três grupos de discussão em São Paulo, Rio Janeiro e Minas Gerais e seus principais resultados mostram a influência de alguns professores formadores na permanência dos discentes no curso de licenciatura; daí a necessidade de os formadores serem conscientes da importância do seu papel no futuro comportamento dos graduandos frente às suas salas de aula; defendem que os cursos de formação inicial privilegiem a troca e a ressignificação das experiências; revelam que o processo de aprendizagem do adulto, futuro professor, e os caminhos que o levam à constituição de sua identidade não são imutáveis nem 
estáticos; que a ação e a identidade docentes se constituem no cotidiano e nas negociações que eles têm de fazer com os estudantes, equipe gestora da escola e com seus pares.

Quanto ao PIBID, ao possibilitar a essas alunas atuação prática nas escolas, permitia que observassem e expressassem a importância da teoria para uma boa prática docente. Assim, segundo os dados, elas não pareciam inclinadas a adotar práticas comodistas ou medíocres em suas aulas. Na pesquisa isso ficou evidenciado por meio da reflexão sobre a própria prática que as pibidianas faziam, e na busca de diferentes caminhos que usavam para alcançar os objetivos propostos nos projetos.

Em Giordan, Hobold e André (2014), as autoras pretenderam "identificar a repercussão da formação continuada no desenvolvimento profissional dos docentes iniciantes na Rede Municipal de Ensino" (p. 39), por meio da realização de entrevistas semiestruturadas com professores efetivos que ingressaram na rede municipal de ensino de uma cidade de Santa Catarina entre 2010 e 2013, tendo de 1 a 3 anos de experiência e atuando nos anos finais do ensino fundamental.

Os resultados indicaram que a formação continuada oferecida aos professores iniciantes é pontual, descontínua, insuficiente, e raramente considera as necessidades desses professores. Portanto, pouco tem contribuído para seu desenvolvimento profissional. Para que isso ocorra, os entrevistados reivindicaram que as ações de formação continuada valorizassem mais a aprendizagem sobre e para a prática, com troca de ideias e experiência entre professores e supervisores de suas áreas de atuação, buscando soluções reais para suas práticas cotidianas. Solicitaram, ainda, a realização de mais cursos, mormente sobre o uso de tecnologias de informação e comunicação e a inclusão de alunos com deficiência.

Os dois outros artigos em parceria (CALIL; ANDRÉ, 2016; SIGNORELLI; ANDRÉ, 2019) são oriundos dos doutorados delas: Calil (2014) e Signorelli (2016).

A tese de Calil (2014) "A formação continuada no município de Sobral (CE)" pretendeu analisar esta política porque a educação neste município apresentava evolução nos indicadores de avaliação e nele se realizava formação continuada específica aos professores iniciantes.

Foram usadas como fontes de dados a entrevista semiestruturada, grupo focal, análise de documento e questionário para captar todo o processo de formação continuada. Participaram da pesquisa dirigentes da Secretaria de Educação e da Escola de Formação de Professores, 11 professores formadores, e 45 professores iniciantes.

O trabalho mostra que, embora o município adote a meritocracia e a política de resultados como referência para a premiação das escolas e suas equipes, a vontade política fez toda a diferença na transformação da sua realidade educacional. Nela a formação continuada é valorizada, a ponto de ter sido criada a Escola de Formação Permanente. Todos os envolvidos nesta passam por formação em exercício e se corresponsabilizam pelos resultados da aprendizagem dos estudantes. O município era, à época, um dos poucos a manter política de formação e acompanhamento dos professores iniciantes.

Os resultados apontaram para o desenvolvimento profissional de todas as instâncias envolvidas no processo de formação continuada, sendo revelada uma correlação com os bons índices de aprendizagem dos estudantes, o que fazia de Sobral objeto de muitas pesquisas. 
O artigo "Uma política de formação voltada aos professores iniciantes de Sobral - CE" (CALIL; ANDRÉ, 2016) faz um recorte da pesquisa de doutorado aqui relatada, especificamente no que concerne aos iniciantes, objetivando analisar a política de formação continuada deles no referido município.

Ressalta a sensibilidade dos gestores da política de Sobral/CE no reconhecimento das necessidades específicas dos iniciantes, levando à implantação de um processo de formação voltado para eles. Destaca o grau de satisfação dos iniciantes sobre a contribuição deste processo formativo para o trabalho de sala de aula e para o desenvolvimento profissional. Realça a dimensão da "eficiência" (VAILLANT; MARCELO, 2012, apud CALIL; ANDRÉ, 2016) que, segundo esses autores, assume um papel psicológico importante, já que em qualquer nível ou área de conhecimento os professores iniciantes desejam orientações sobre como proceder com eficiência na sala de aula.

Por sua vez, a pesquisa de doutorado de Gonçalves" (2016), "Inserção profissional de egressos do Pibid: desafios e aprendizagens do início da docência", pretendeu trazer contribuições para o entendimento do início da carreira, considerada como fase crucial do ciclo profissional. O pressuposto foi que "o Pibid, ao trazer subjacente a ideia da formação inicial integrada às escolas básicas, amplia a convivência dos licenciandos com a prática docente, potencializa a formação inicial e ameniza as condições adversas sofridas pelos professores em início de carreira" (p. 8). A inserção profissional dos professores é considerada como um período de incerteza, instabilidade e tensão, a par de ser para muitos a passagem para a vida adulta. Além disso são raros os apoios aos iniciantes.

Foram feitos grupos de discussão com 12 professoras iniciantes, ex-pibidianas e egressas do curso de Pedagogia de uma universidade pública federal de Minas Gerais; questionário; entrevistas semiestruturadas com sete diretoras e supervisoras das escolas básicas onde atuam essas professoras; e análise documental do PPC da instituição formadora. A análise dos dados se deu por meio do método de 'análise de prosa' (ANDRÉ, 1983).

Os resultados revelaram dificuldades e tensões, descobertas e aprendizagens na inserção profissional das ex-pibidianas. Mostraram também que tanto a formação inicial no curso de Pedagogia, como a participação no Pibid foram fundamentais a esta inserção. A dinâmica proporcionada pela aproximação universidade-escola, por meio da ação/reflexão/ação e de uma lógica teórico-prática proporcionou que elas respondessem com conhecimento e criatividade aos problemas e necessidades da prática pedagógica. Enfim, o PIBID é considerado como experiência de sucesso, tanto para a formação como para a inserção profissional dos futuros professores.

A tese originou a publicação do artigo "Contribuições do programa institucional de bolsas de iniciação à docência (PIBID) para a inserção profissional de professoras iniciantes" (SIGNORELLI; ANDRÉ, 2019) e indicando, em ponto pequeno, os resultados da pesquisa de doutorado.

\subsection{Sobre a compreensão do processo de início da docência e da direção de escola}

Os registros do CV Lattes apontam que, nesta categoria, Marli André publicou 5 artigos em coautoria, sendo 3 oriundos das dissertações e teses orientadas por ela. Destas, duas versavam sobre diretores de escola iniciantes e as demais sobre o início da docência.

4 Nos outros trabalhos a autora consta como Signorelli. 
A dissertação de Silva (2018), "Necessidades Formativas dos diretores de escola iniciantes na Rede Municipal de Ensino de São Paulo", além de conhecer as necessidades formativas e os desafios enfrentados na gestão da escola por eles, propôs apontamentos para ações de formação.

Os dados advieram de entrevista semiestruturada com 3 diretores de escola pertencentes a uma Diretoria Regional de Educação daquela rede municipal, com até três anos de experiência no cargo; de análise da legislação pertinente ao tema; e de documentos da Secretaria Municipal de São Paulo. A análise dos dados foi feita por meio da 'análise de prosa' (ANDRÉ, 1983).

Os resultados evidenciaram, em suma, que: a decisão de se tornarem diretores foi tomada em função de dificuldades enfrentadas no exercício da docência, mas eles não esperavam encontrar tantas também no desempenho da função de diretor. Entre elas citaram principalmente: aspectos burocráticos e de legislação; mediação de conflitos; relações interpessoais; rotina e organização do trabalho; e aspectos relacionadas à conjuntura e às políticas públicas educacionais. Silva $(2018$, p. 97) alude a um 'choque do real' também quanto à função gestora, o que não impede os diretores de estarem felizes no desempenho dela. Para lidar com os desafios os diretores informaram buscar apoio na equipe gestora da escola, em colegas mais experientes, na supervisão e na diretoria regional de ensino. As necessidades formativas por eles apontadas relacionam-se às questões práticas do fazer cotidiano e ao funcionamento da escola.

Diniz (2020), na dissertação "Os percalços e necessidades no caminho do professor iniciante", objetivou "identificar os principais desafios e dificuldades enfrentados por um grupo de professores iniciantes, alocados nas redes particular e pública de municípios do estado de São Paulo" (p. 8) [e] "identificar as estratégias utilizadas por esses professores para responder às adversidades em suas práticas profissionais, bem como conhecer suas necessidades formativas" (p. 8).

Os dados foram obtidos por meio de questionário e os resultados apontaram como desafios e dificuldades: condições de trabalho e suas implicações - desvalorização salarial e de reconhecimento social; falta de parceria entre os pares, gestão e família; ausência de recursos e de formação adequados. Os participantes apontaram que procuravam resolver de formas variadas suas dúvidas e que se preocupavam em inovar e cuidar da aprendizagem do aluno. Isso valeu a afirmação da autora de que eles se revelaram "especialistas adaptativos" (p. 8).

Foram dadas indicações de como a identificação e o conhecimento das necessidades formativas dos iniciantes podem contribuir para planificar processos formativos, visando ao desenvolvimento profissional contínuo e à redução dos percalços iniciais da docência.

Na pesquisa de doutorado intitulada "O início da docência de professores do ensino superior", Hees (2016) teve como objetivo "analisar como os profissionais docentes vivenciam o início da docência em um centro universitário confessional" (p. 8). Para isso, analisou a legislação da educação superior, as qualidades necessárias ao professor da educação superior, a profissionalidade e o desenvolvimento docente no início da carreira profissional.

Os 12 participantes foram selecionados por meio da análise documental do PDI da universidade e responderam a uma entrevista semiestruturada sobre: quem é o docente iniciante na educação superior; seus desafios e dificuldades do início de carreira; suas necessidades formativas; e como o ambiente institucional influencia a constituição docente. 
Segundo a autora, o docente iniciante na educação superior é responsável pela sua inserção, "é ele que tem que encontrar a maneira de adaptar-se e sobreviver a sua realidade profissional" (p. 8). As principais preocupações identificadas no início da docência foram o domínio dos conhecimentos a serem ensinados e a "necessidade de impor a autoridade através do papel que exerce" (p. 8). Com relação às especificidades do ambiente institucional, os participantes demonstraram o "desejo de fazer parte" e de se "adequar ao contexto da instituição" (p. 8), o que é favorecido pelo clima organizacional da IES. Como desafios mencionaram: ser reconhecidos e legitimados pelos pares; lidar com a competição acadêmica e com a falta de tempo e de convívio que permitam trocas e diálogos.

A autora aponta elementos coerentes com a proposta da IES para elaboração da proposta de apoio aos docentes iniciantes: habilitá-los para utilizar o método andragógico e a articular teoria e prática no ensino; proporcionar grupos de discussão das atividades pedagógicas entre os professores; viabilizar programa de mentoria; acolhê-los nos grupos de pesquisa, entre outros.

O artigo "Inserção de professores em início de carreira no Ensino Universitário" (HEES, ANDRÉ, SOUZA, F.; SOUZA, D., 2018), embora não o explicite no texto, é derivado da referida tese. Focaliza alguns elementos para a implantação de um programa de apoio aos professores iniciantes na Educação Superior. Seus resultados coincidem com os da pesquisa de doutorado de Hees (2016).

A tese de doutorado de Príncepe (2017), "Condições de trabalho e desenvolvimento profissional de professores iniciantes em uma rede municipal de educação", buscou "investigar as implicações das condições de trabaIho no desenvolvimento profissional de professores iniciantes em uma Rede Municipal de Educação (RME). Buscou-se caracterizar os professores iniciantes; identificar os contextos em que atuam; analisar as condições de trabalho e identificar os fatores que favorecem ou dificultam o seu desenvolvimento profissional" (p. 10).

A pesquisa, tipo survey, envolveu 121 docentes, dos quais 60 iniciantes na profissão e na rede e 61 iniciantes na rede, que responderam a um questionário; analisou documentos de orientação administrativo-pedagógicos; realizou entrevistas com 3 formadoras da RME; e utilizou dados do Censo Escolar de 2014 e 2015 e do Censo Demográfico de 2010.

O maior destaque nos resultados foi dado às condições de trabalho que para a maioria dos participantes envolviam instabilidade e descontinuidade. O curto período de permanência em uma única escola; a atuação em diversas turmas ao mesmo tempo; e a vivência de jornadas diferenciadas configuram um conjunto de condições que traz grande complexidade ao trabalho, dificultando as tarefas referentes ao planejamento escolar; ao conhecimento dos alunos e do próprio contexto de atuação; ao estabelecimento de vínculos com os pares de trabalho. Ademais, dificultam-se sobremaneira as possibilidades da efetivação de ações formativas situadas na escola, que sejam favoráveis à aprendizagem da docência.

A pesquisadora indica, ainda, que a delimitação do tempo do que pode ser considerado "início da docência" depende das condições de carreira e não pode ser generalizada. Sugere que "enquanto o professor não alcançar estabilidade e continuar vivenciando suas experiências profissionais em condições de precariedade, poderá ser considerado iniciante" (p. 10).

Desta pesquisa de doutorado foram derivados os artigos "Fatores facilitadores e dificultadores do desenvolvimento profissional de professores iniciantes: uma análise das condições de trabalho" (PRÍNCEPE; ANDRÉ, 2018) e "Condições de trabalho na fase de indução profissional dos professores" (PRÍNCEPE; ANDRÉ, 2019). Nelas 
o recorte feito na pesquisa maior reitera e realça os resultados e conclusões desta, em especial - a meu ver, e com risco de ser reiterativa - a de que "os limites do tempo do que pode ser considerado 'início da docência' dependem das condições de carreira e enquanto o professor não alcançar a estabilidade e continuar vivenciando suas experiências profissionais em condições de precariedade, poderá ser considerado iniciante" (p. 3).

Encontra-se, ainda, no CV Lattes o registro da publicação dos artigos "O papel do outro na constituição da profissionalidade de professoras iniciantes" (ANDRÉ; CALIL; MARTINS; PEREIRA, 2017) e "Professores iniciantes dos anos finais do ensino fundamental: indicação das necessidades formativas" (GIORDAN; HOBOLD; ANDRÉ, 2017).

O primeiro (ANDRÉ; CALIL; MARTINS; PEREIRA, 2017) focaliza "o processo de constituição da profissionalidade de professores iniciantes, buscando identificar os principais desafios enfrentados em suas práticas cotidianas na educação infantil e nos anos iniciais da educação básica" (p. 505), além de analisar os elementos que afetam a identidade e o desenvolvimento profissional desses professores.

A pesquisa desenvolveu-se por meio de 4 grupos de discussão com egressos do curso de pedagogia de três universidades e de uma faculdade do interior do estado de São Paulo. Os principais resultados indicaram que "as relações empreendidas no cotidiano escolar, seja com os pais de alunos, seja com os gestores da escola, com colegas mais experientes ou com os alunos têm peso considerável na constituição da profissionalidade desses professores e afetam sua identidade profissional" (p. 505).

O segundo (GIORDAN; HOBOLD; ANDRÉ, 2017), tendo como participantes professores iniciantes do $6^{\circ}$ ao $9^{\circ}$ ano do ensino fundamental da Rede Municipal de Ensino de Joinville, objetivou apresentar as necessidades formativas destes professores, que ingressaram entre 2010 e 2013, sendo considerados iniciantes em um novo contexto de trabalho.

A obtenção dos dados deu-se por entrevista semiestruturada, cujos resultados indicaram, principalmente que: os professores solicitaram que os momentos de formação continuada privilegiassem a troca de ideias/ experiências entre eles, sendo então planejados para que ocorresse tal interlocução. Também sinalizaram a necessidade de ampliação da quantidade de cursos para o aprimoramento profissional.

Duas temáticas foram apontadas como relevantes para o trabalho dos entrevistados: como utilizar tecnologias e como lidar com a inclusão de alunos com deficiência, pois tais temáticas não foram efetivamente trabalhadas na formação inicial, gerando a necessidade de serem abordadas na formação continuada.

\section{Apontando alguns destaques}

\subsection{Sobre políticas e programas de inserção/indução profissional}

Importante contribuição de Marli André adveio de seu envolvimento em pesquisas de grande porte sobre políticas e programas de inserção/indução profissional, das quais são citadas duas em seu CV Lattes: Gatti et al. (2011, op. cit) e André (2013). Da primeira resultaram 3 artigos (ANDRÉ, 2012; 2013; 2015) e da segunda um (ANDRÉ, 2018).

Das principais conclusões, apresentadas na seção 3.1, o destaque é para a potencial contribuição dessas pesquisas às políticas públicas educacionais voltadas à formação continuada e ao desenvolvimento profissional 
de professores, com ênfase à fase de iniciação à docência, momento de especial relevância na carreira, o que é farta e profundamente justificado nas produções analisadas.

Assim, os resultados de tais pesquisas, sérias e rigorosas, revelam o valor do apoio à formação continuada de professores, em especial aos recém-ingressos na profissão ou em uma rede de ensino. As produções valorizam experiências formativas de programas como PIBID (âmbito federal); Bolsa Alfabetização (âmbito estadual/SP); e Residência Pedagógica (âmbito institucional/UNIFESP/campus Guarulhos).

\subsection{Sobre conceitos-chave e seu significado}

Sem descurar de outros conceitos importantes presentes na obra da autora, avalio como principais:

\subsubsection{Desenvolvimento profissional docente (DPD)}

Na minha leitura, é conceito-chave para todos os demais, já que a aprendizagem do início da docência é vista como primeira e fundamental fase desse processo.

Desenvolvimento profissional, de acordo com Príncepe e André (2018):

remete a um movimento de transformação, constituição e aperfeiçoamento em uma comunidade profissional e de acordo com García (1999) tem uma conotação de evolução e continuidade, superando a justaposição entre a formação inicial e a formação contínua de professores e por este motivo, se adequa melhor à concepção de professor como profissional de ensino. Além disso, o termo pressupõe uma abordagem da formação de professores que "[...] valorize seu caráter contextual, organizacional e orientado para a mudança (GARCÍA, 1999, p. 137).

As autoras enfatizam o caráter contínuo do DPD, sendo um processo a longo prazo que ocorre durante toda a carreira profissional dos professores, correspondendo à concepção de 'formação ao longo da vida'. Ele precisa ser integrado por diferentes tipos de oportunidades e experiências planejadas intencional e sistematicamente, visando à promoção de mudanças no sentido de apoiar os docentes para que respondam adequadamente às exigências e desafios postos por seus contextos de trabalho.

Em defesa da não dicotomia entre formação inicial e continuada, Giordan, Hobold e André (2014) defendem que seria mais adequado melhorar o desenvolvimento profissional dos professores, em especial no que concerne à inserção na carreira, do que aumentar a duração da formação inicial.

\subsubsection{Formação continuada}

O DPD se dá por meio de processos de formação continuada (FC). André (2015) cita, entre outros, Imbernón (2009, apud ANDRÉ, 2015) que indica como essenciais à FC: aspectos ligados à subjetividade dos docentes (emoções, sentimentos, autoestima, empatia); ao domínio dos conhecimentos profissionais (saberes vinculados ao ensino para fazer com que os estudantes aprendam); à dimensão institucional (mudanças nos contextos de trabalho).

A autora faz defesas importantes, em especial a da criação de uma cultura colaborativa na escola, aliada à de que não sejam apenas feitas 'cobranças' à formação dos professores, mas que thes sejam proporcionadas as condições para o exercício da docência, tais como, minimamente: material didático-pedagógico, espaço 
físico adequado, número razoável de alunos por turma, 'clima' propício de relações interpessoais, assessoria sobre currículo e didática.

\subsubsection{Professores iniciantes, professores ingressantes e indução profissional}

Esta terminologia vem sendo objeto de disputa semântica entre os produtores de conhecimento da área. Entendo que para André, seus coautores e orientandas, os três termos são empregados com significado análogo, referindo-se aos professores com até 3 anos de experiência docente e àqueles que, mesmo tendo iniciado há mais tempo, venham a ingressar em outra rede ou situação de ensino.

Para a primeira parte da definição - docentes com até 3 anos de experiência - André se pauta em Huberman (2013), autor que considera a fase de entrada na carreira como a primeira do ciclo de vida profissional docente. Para a segunda parte - relativa ao reingresso em uma situação de ensino diferente (rede de ensino por exemplo) - a inspiração teórica vem dos trabalhos de Burke; Christensen; Fessler (1984, apud PRÍNCEPE, 2017), Marcelo García (1999, apud PRÍNCEPE, 2017), entre outros.

Também no artigo de Giordan, Hobold e André (2014, p. 43-44) lê-se:

neste estudo, professores iniciantes [são] os que estão ingressando nessa Rede de Ensino, independente do tempo de experiência na docência, considerando que estão entrando em um novo contexto de ensino com características próprias. Acredita-se, assim como Marcelo Garcia (1999), que as características do início da docência não se relacionam apenas ao tempo de experiência docente, mas podem variar de acordo com a situação de ensino ou mudança de Redes de Ensino.

Nas publicações em que é empregado, o termo 'ingressante' tem a acepção de 'iniciante', como se observa em André $(2012 ; 2015 ; 2018)$ e em Giordan, Hobold e André $(2014 ; 2017)$.

O mesmo ocorre com a expressão 'indução', que equivaleria à 'fase de entrada na carreira':

O início na carreira docente ou fase de indução é aqui entendido como o período que marca a entrada no campo profissional (a escola), após a conclusão da formação inicial, compreendendo os três primeiros anos de exercício, de acordo com Huberman (2013) [...] (PRÍNCEPE; ANDRÉ, 2018, p. 4, grifo meu).

Avalio como avanço, em relação ao acúmulo até então obtido, a conclusão de Príncepe (2017) de que "enquanto o professor não alcançar estabilidade e continuar vivenciando suas experiências profissionais em condições de precariedade, poderá ser considerado iniciante" (p. 10).

\subsubsection{Diretores iniciantes}

Com relação a este tema, ainda menos explorado que o dos docentes, o CV Lattes registra a dissertação de Silva (2014) e a de Francisco (2020). Apesar da pouca quantidade de evidências aportada por duas pesquisas, os resultados e conclusões apresentadas na seção 3.2 deste artigo revelam algumas similitudes com o início da docência, como, por exemplo, certo 'choque do real', provavelmente correspondente aos aspectos da 'sobrevivência' (Huberman, 2013); busca de apoio em colegas de sua confiança; necessidades formativas de natureza mais prática (como fazer); alegação de dificuldades postas pelas condições de trabalho, tais como: desvalorização social e salarial, falta de parceria entre colegas, gestores e familiares dos estudantes, queixas quanto à formação - quantidade e qualidade. 


\subsubsection{Necessidades formativas}

Em grande parte dos trabalhos analisados encontra-se a defesa da importância do estudo das necessidades formativas dos docentes como base para a planificação e execução das ações de formação continuada e DPD, a exemplo de André (2012; 2013; 2015) Giordan, Hobold e André (2014), Calil e André (2016); André, Calil, Martins e Pereira (2017); Príncepe e André (2018; 2019).

Embora concordando com esta defesa, entendo que ela corresponde à dimensão subjetiva das necessidades formativas, isto é, a como os professores e diretores de escola percebem suas necessidades. Porém, defendo, com Benedito, Imbernón e Félez (2001), que seja considerada também sua dimensão objetiva, correspondente àquilo que a profissão exige dos docentes e diretores atualmente. Abordo essas ideias de forma mais alentada em Lima (2015), ainda que em relação ao ensino superior.

\subsection{Sobre metodologia das pesquisas}

Todas as pesquisas empreendidas por Marli André ou por ela orientadas são qualitativas, à exceção de duas (ANDRÉ, 2018 e PRÍNCEPE, 2017). Mesmo estas, sendo surveys, empregaram técnicas quantitativas de obtenção dos dados, porém suas análises são qualitativas. Além desses, observa-se o envolvimento da autora em inúmeras outras pesquisas de grande porte ao longo de sua trajetória profissional, o que a autorizou a aliar a teoria - domínio em que se notabilizou pelas contribuições à pesquisa em Educação no Brasil - à prática da pesquisa de qualidade, servindo de referência e de exemplo a várias gerações de pesquisadores.

Sua expertise na orientação de dissertações e teses merece relevo, tanto pela qualidade dos produtos quanto pela notória distinção entre as primeiras e as segundas. Enquanto as dissertações são pesquisas de menor âmbito, no mais das vezes envolvendo uma fonte de dados, nas teses as pesquisas são robustas, com múltiplas fontes de dados e sua triangulação. Não obstante as aludidas diferenças, todas primam pelo rigor teórico e teórico-metodológico.

Chama a atenção o uso, na maioria das dissertações e teses consideradas, do método de 'Análise de prosa', criado pela autora e divulgado em André (1983). Em suma, sugere que em lugar de um sistema pré-especificado de categorias, vão sendo gerados tópicos e temas partindo dos dados e de sua contextualização. Eles devem ser "frequentemente revistos, questionados, reformulados, na medida em que a análise se desenvolve, tendo em vista os princípios teóricos e os pressupostos da investigação" (p. 67). 


\section{Considerações finais}

A primeira constatação que salta aos olhos ao considerar esta parcela da produção de Marli André é - reitero - a qualidade da sua contribuição para a elaboração de políticas públicas. Insisto nesta afirmação no intuito de desautorizar frontalmente as autoridades governamentais e das agências de fomento à pesquisa a alegarem a ausência de contribuição de pesquisadores e pesquisadoras brasileiras para este mister. E só posso chegar a uma conclusão: a de que a visão dessas 'autoridades' é propositalmente seletiva!

Finalmente, deixo o convite para que pesquisadores(as) interessados(as) na temática da construção profissional do início da docência revisitem o presente artigo, na perspectiva de complementá-lo ou de debater a minha leitura sobre as contribuições da querida e inesquecível Marli André. 


\section{REFERÊNCIAS}

ANDRÉ, Marli E. A. D. Texto, contexto e significado: algumas questões na análise de dados qualitativos. Cadernos de Pesquisa, São Paulo (45): 66-71, maio 1983.

ANDRÉ, Marli Elisa D. A. Políticas e programas de apoio aos professores iniciantes no Brasil. Cadernos de pesquisa, São Paulo, v.42 n.145 p.112-129 jan./abr. 2012.

ANDRÉ, Marli Elisa D. A. Professores iniciantes: egressos de programas de iniciação à docência. Revista Brasileira de Educação, Rio de Janeiro, v.23. 2018.

ANDRÉ, Marli Elisa D. A. Políticas de apoio aos docentes em estados e municípios brasileiros: dilemas na formação de professores. Educar em Revista, Curitiba, n. 50, p. 35-49, out./dez. 2013.

ANDRÉ, Marli Elisa D. A. Políticas de formação continuada e de inserção à docência no Brasil. Educação Unisinos, Porto Alegre, 19(1):34-44, janeiro/abril 2015.

ANDRÉ, Marli Elisa D. A.; CALIL, Ana Maria G. C.; MARTINS, Francine de Paulo; PEREIRA, Marli Amélia Lucas. O papel do outro na constituição da profissionalidade de professoras iniciantes. Revista Eletrônica de Educação, v.11, n.2, p. 505-520, jun./ago., 2017.

BARBOSA Rafael Conde; ALFONSI Selma; BACHIEGGA, Sylvia; ANDRÉ, Marli Elisa D. A. Um momento importante na formação dos licenciandos do pibid: a transição de aluno a professor e a constituição de sua identidade profissional. Olh@res, Guarulhos, v. 2, n. 1, p. 302-319. Maio, 2014.

BENEDITO, Vicente A.; IMBERNÓN, Francisco M.; FÉLEZ, Beatriz R. Necesidades y propuestas de formación del profesorado novel de la Universidad de Barcelona: profesorado. Revista de Currículum y Formación del Profesorado, Granada, España, v. 5, n. 2, p. 1-24, 2001. Disponível em: <http://hdl.handle.net/10481/19020>. Acesso em: 30 mar. 2013.

CALIL, Ana Maria G. C. A formação continuada no município de Sobral (CE). Tese de Doutorado em Educação - Psicologia da Educação - Pontifícia Universidade Católica de São Paulo. São Paulo, 2014.

CALIL, Ana Maria G. C.; ANDRÉ, Marli Elisa D. A. Uma política de formação voltada aos professores iniciantes de Sobral - CE. Rev. Diálogo Educ., Curitiba, v. 16, n. 50, p. 891-909, out./dez. 2016.

DINIZ, Thaís. Os percalços e necessidades no caminho do professor iniciante. Dissertação de Mestrado Profissional em Educação: Formação de Formadores. Pontifícia Universidade Católica de São Paulo. São Paulo/SP, 2019.

FRANCISCO, Rosangela de Lima. Profissão diretor: contribuições de um curso semipresencial para a formação dos ingressantes da rede estadual de ensino de São Paulo. Dissertação de Mestrado Profissional em Educação: Formação de Formadores. Pontifícia Universidade Católica de São Paulo. São Paulo/SP, 2020.

GIORDAN, Miriane Z.; HOBOLD Márcia de S.; ANDRÉ, Marli Elisa D. A. Professores iniciantes da rede municipal de ensino: formação continuada e os reflexos no desenvolvimento profissional. Revista Cocar, Belém/ PA, vol 8, n. 16, p. 39-51. Ago-Dez, 2014. 
GIORDAN, Miriane Z.; HOBOLD Márcia de S.; ANDRÉ, Marli Elisa D. A. Professores iniciantes dos anos finais do ensino fundamental: indicação das necessidades formativas. Educação: Teoria e Prática/ Rio Claro, SP/Vol. 27, n.55/ p.308-326/ Mai-Ago. 2017.

GONÇALVES SIGNORELLI, Glaucia. Inserção profissional de egressos do Pibid: desafios e aprendizagens do início da docência. Tese de Doutorado em Educação -Psicologia da Educação - Pontifícia Universidade Católica de São Paulo. São Paulo, 2016.

HEES, Luciane Weber B. O início da docência de professores da Educação Superior. Tese de Doutorado em Educação -Psicologia da Educação - Pontifícia Universidade Católica de São Paulo. São Paulo, 2016.

HEES, Luciane Weber B.; ANDRÉ, Marli Elisa D. A.; SOUZA, Francislê Neri; BRITO, Dayse Cristine Dantas. Inserção de professores em início de carreira no Ensino Universitário. Indagatio Didactica, vol. 10 (5), dezembro 2018.

HUBERMAN, Michaël. O Ciclo de vida profissional dos professores. In: NÓVOA, A. (Org.). Vidas de professores. 2. ed. Portugal: Porto Editora, 2013. p. 31-61.

LIMA, Emília F. de. Análise de necessidades formativas de docentes ingressantes numa universidade pública. Rev. bras. Estud. pedagog. (online), Brasília, v. 96, n. 243, p. 343-358, maio/ago. 2015.

PRÍNCEPE Lisandra; ANDRÉ, Marli Elisa D. A. Condições de trabalho na fase de indução profissional dos professores. Currículo sem Fronteiras, v. 19, n. 1, p. 60-80, jan./abr. 2019.

PRÍNCEPE Lisandra; ANDRÉ, Marli Elisa D. A. Fatores facilitadores e dificultadores do desenvolvimento profissional de professores iniciantes: uma análise das condições de trabalho. Revista de Estudos Aplicados em Educação, v. 3, n. 6, jul./dez., 2018.

PRÍNCEPE, Lisandra. Condições de trabalho e desenvolvimento profissional de professores iniciantes em uma rede municipal de educação. Tese de Doutorado em Educação - Psicologia da Educação - Pontifícia Universidade Católica de São Paulo. São Paulo, 2017.

SIGNORELLI, Glaucia; ANDRÉ, Marli Elisa D. A. Contribuições do programa institucional de bolsas de iniciação à docência (PIBID) para a inserção profissional de professoras iniciantes. Rev. Devir Educação, Lavras, vol.3, n.2, p.27-52 jul./dez., 2019.

SILVA, Cristiane Ferreira da. Necessidades Formativas dos diretores de escola iniciantes na Rede Municipal de Ensino de São Paulo. Dissertação de Mestrado Profissional em Educação: Formação de Formadores. Pontifícia Universidade Católica de São Paulo. São Paulo/SP, 2018.

LIMA, E. F.; Contribuições da professora Marli André para a produção de conhecimento sobre professores iniciantes. Formação Docente - Revista Brasileira de Pesquisa sobre Formação de Professores. Belo Horizonte. Vol. 13, no 28 (p. 101-118) 31 dez. 2021. ISSN: 2176-4360. DOI https://doi.org/10.31639/rbpfp.v13i28.539 
